\title{
ESTIMATION OF TIME LENGTHS OF CELL-CYCLE PHASES FROM ASYNCHRONOUS CULTURES OF THE BASIDIOMYCETOUS YEAST RHODOSPORIDIUM TORULOIDES
}

\author{
KEIKO ABE, SAKUZO FUKUI ${ }^{1}$ AND AKIO KUSANAGI* \\ The Institute of Applied Microbiology, University of Tokyo, \\ Bunkyo-ku, Tokyo 113, Japan \\ *Department of Biology, Yokohama-City University, Kanazawa-ku, \\ Yokohama 236, Japan
}

(Received June 1, 1984)

\begin{abstract}
Phase-lengths in the cell division cycle of the basidiomycetous yeast Rhodosporidium toruloides Banno in an asynchronous culture at $27^{\circ}$ were estimated by using three parameters: cell morphology, DNA synthesis, and nuclear behavior. In the yeast-extract-sucrose medium, one division cycle is $160 \mathrm{~min}$, and phase-lengths of $\mathrm{G} 1, \mathrm{~S}, \mathrm{G} 2$, and $\mathrm{M}$ are calculated to be $116 \mathrm{~min}, 27 \mathrm{~min}, 10 \mathrm{~min}$, and $7 \mathrm{~min}$, respectively, by applying Powell's distribution function. As a dynamic phenomenon, the cell division cycle was presented in a cell clock.
\end{abstract}

In previous papers (1-4), we reported the discovery, isolation, chemical structure, and chemical synthesis of a mating hormone "Rhodotorucine A," which is constitutively produced by a haploid yeast of Rhodosporidium toruloides Banno IFO-0559-M-919 (mating type $A$ ) and induces sexual differentiation (alteration in generation from vegetative haploid cell to gamate cell) in a haploid yeast of $R$. toruloides IFO-0880-M-1057 (mating type $a$ ). The morphological events in the early stages of the mating process in the life cycle of the yeast Rhodosporidium toruloides are the repression of new bud-emergence and the induction of matingtube formation $(1,5)$. The mating-tube-forming cell contains a single nucleus and elongates the tube without duplication of the nucleus (5). Thus, the cessation of the cell division cycle at the definite stage and the activation of the trigger reaction, repressed during the progression of mitotic cell division cycle, are essential for the induction of sexual differentiation. In order to analyze the alteration in generation, it is important to clarify the sequential events required for the pro-

1 Present address: Department of Fermentation Technology, Faculty of Engineering, University of Hiroshima, Higashi-Hiroshima, Japan. 
gression of the cell division cycle. In our research group, several mutant-strains of temperature-sensitive cell division cycle, $c d c$ mutants, have been isolated, and some of them were characterized (6).

Cell division cycle of eukaryotes is commonly divided into four phases: G1 (gap 1, a period prior to DNA synthesis), S (a period of DNA synthesis), G2 (gap 2, a period between termination of DNA synthesis and initiation of mitosis), and $\mathrm{M}$ (a period of mitosis). In this paper, we estimate the time length of each phase of Rhodosporidium toruloides, a basidiomycetous yeast, and present the cell division cycle as a cell-clock from three dynamic paramaters: cell morphology, nuclear behavior, and DNA synthesis.

\section{MATERIALS AND METHODS}

Microorganisms. Rhodosporidium toruloides IFO-0880-M-1057 (haploid, mating type $a$ ) and IFO-0559-M-919 (haploid, mating type $A$ ) (7) were used, though there was no difference in cell division cycle between them. Therefore, the results obtained with the former strain are presented here.

Medium and cultivation. Yeast-extract-sucrose medium (YS medium) used was described in the previous paper (1). All cultivation was at $27^{\circ}$. Seed culture was carried out in a test tube $(16 \times 180 \mathrm{~mm})$ containing $5 \mathrm{ml}$ of YS medium with shaking (1), and was used as an inoculum at a log-growth phase (approximately $10^{7}$ cells per $\mathrm{ml}$ ). For determination of the time lengths of cell stages (phases) in the cell division cycle, an asynchronous culture in a liquid YS medium was performed in an Erlenmyer-flask $(50 \mathrm{ml})$ with gentle stirring. Doubling time was $160 \mathrm{~min}$ under the conditions used here. At an exponential growth phase of the culture, cells were fixed onto a slide glass as described in the previous paper (5), then the fixed cells were stained with Giemsa-reagent. Cell morphology (cellular events) and nuclear features (nuclear events) observed in the Giemsa-stained specimens were employed as parameters for definition of cell stages in the cell division cycle. The time length of each cell stage defined in RESULTS was calculated by Powell's distribution function (8) which has been applied to an asynchronous culture of exponentially growing yeast Saccharomyces cerevisiae Hansen (9).

Autoradiography. In order to determine the length of $\mathrm{S}$ phase, an autoradiographic method (10) was used as described below. When the cell density of the culture reached approximately $10^{7}$ cells per $\mathrm{ml}$ in a liquid YS medium, a $50-\mu \mathrm{Ci}$ amount of radioactive adenine $\left(2\left[{ }^{3} \mathrm{H}\right]\right.$ adenine, $250 \mathrm{mCi} / \mathrm{mmole}$, Radiochemical Center Amersham, U.K.), was added to $1 \mathrm{ml}$ of the culture, and $15 \mathrm{~min}$ of further cultivation was performed. $1 \mathrm{ml}$ of the culture was then poured into $1 \mathrm{ml}$ of a previously ice-colded $2 \mathrm{~N} \mathrm{NaOH}$. Alkaline treatment (in $1 \mathrm{~N} \mathrm{NaOH}$ ) of the culture was carried out for $24 \mathrm{hr}$ at $20^{\circ}$ to extract RNA from the cells, followed by dilution with $8 \mathrm{ml}$ of distilled water. A small amount of the diluted 
alkali-treated-culture was placed on a slide glass for $30 \mathrm{~min}$ to sediment the cells on the glass, after which the water over the cells was gently removed. The cells on the glass were carefully washed with distilled water and dried in the air. After drying, autoradiograms of the cells on the glass were prepared in the usual manner. The emulsion used was Sakura-Autoradiographic Emulsion NRM2, and exposure time was 2 weeks at $4^{\circ}$. The number of silver grains deposited on each cell were counted under a light microscope (Olympus BHB-113).

Observation of individual growing-cells. Seed culture was transferred onto an agar film of YS medium, followed by incubation for microculture (1). The microculture was at $27^{\circ}$. The progression of cell stages in the individual livingcell was traced as time-lapse alterations in both cell morphology and nuclear features under a phase-contrast microscope. Micrographs were taken at 5-min interval.

\section{RESULTS}

Estimation of the lengths of cell stages in cell division cycle of Rhodosporidium toruloides

Previously, we reported the characteristic features of mitotic nuclear-division in a strain $R$. toruloides IFO 0880-M-1057 (M-1057), a budding yeast, in which

Table 1. Definition of cell stages.

\begin{tabular}{|c|c|c|c|c|c|c|}
\hline \multirow{2}{*}{ Stage } & \multirow{2}{*}{ Form and state } & \multicolumn{2}{|c|}{ Cell } & \multicolumn{3}{|c|}{ Nucleus } \\
\hline & & Number & Bud & Number & State $^{a}$ & Distribution \\
\hline I & & 1 & - & 1 & Expanding & Mother part \\
\hline II & & 1 & + & 1 & Expanding & Mother part \\
\hline III & & 1 & + & 1 & Expanding & Neck part \\
\hline IV & & 1 & + & 1 & Compact & Bud part \\
\hline V & & 1 & + & 2 & Compact & Bud part \\
\hline VI & & 1 & + & 2 & Compact & $\begin{array}{l}\text { Mother and } \\
\text { bud parts }\end{array}$ \\
\hline VII & & 2 & - & 2 & Expanding & $\begin{array}{l}\text { Mother and } \\
\text { dauther parts }\end{array}$ \\
\hline
\end{tabular}

a Nuclear states are clearly characterizable under a microscope using nuclear-stained specimens (5).

Open and closed circles indicate expanding and compact nuclei, respectively. Left-hand and right-hand cells are mother and bud (daughter) parts, respectively. 
Table 2. Time lengths of cell stages.

\begin{tabular}{crc}
\hline Cell-stage & Cell number & Time length $^{a}$ \\
\hline I & 1,771 & $52.6 \mathrm{~min}$ \\
II & 1,467 & 55.0 \\
III & 140 & 6.1 \\
IV & 80 & 3.6 \\
V & 18 & 0.8 \\
VI & 57 & 2.6 \\
VII & 808 & 39.4 \\
Total & 4,341 & 160 (one generation)
\end{tabular}

$a \quad$ Time lengths were calculated by applying Powell's distribution function (8).

Relative cell-number $(R)$ at a cell-age $(X)$ in a cell division cycle is defined as follows:

$R=f(X)=\ln 2 \cdot 2^{1-X}$

where $X$ is a variable from 0 to 1 . Thus, $R$ at a cell-stage from cell-age of $a$ to $b$ is

$R=\int_{a}^{b} f(X) \mathrm{d} X=2\left(2^{-a}-2^{-b}\right)$.

Time lengths are obtainable from $R$.

nuclear division takes place in the bud part of the cell (5). In this section, therefore, cell division cycle was divided into seven stages from two legible and visible parameters, cell morphology and nuclear features observed with Giemsa-stained specimens, and the estimation of time length of each cell stage was performed. The definition of each cell-stage is as follows: Stage I, cell is a single cell without bud and has a nucleus which locates at a central zone of the cell (mother part) as an expanded form; Stage II, cell has a bud and a nucleus which takes the same figure as that in Stage I; Stage III, cell has a relatively large bud and a nucleus which migrates to a neck zone of the cell as an expanded form; Stage IV, cell has a large bud and a nucleus which is in a bud part and alters to a compact form; Stage $V$, cell has a large bud and two nuclei which are in a bud part as a compact form (nuclear division takes place in bud part); Stage VI, cell has a large bud and two compact-formed nuclei, one nucleus in mother part and another in bud part; Stage VII, each of mother and bud parts has a nucleus in an expanded form, and bud still connects with mother part. The definition described is schematically summarized in Table 1. Time lengths of these cell-stages were calculated by applying Powell's distribution function (footnote in Table 2). As seen in Table 2, the lengths of the seven stages, I to VII, are 52.6, 55.0, 6.1, 3.5, 0.8, 2.6, and 39.4 min, respectively (YS medium).

Estimation of the length and timing of $M$ phase, mitotic nuclear-division phase

When a period of $\mathrm{M}$ phase is defined as a period giving a compact-formed nucleus in Giemsa-stained specimens, the length corresponds to a total of the three cell-stages, IV, V, and VI, $7.0 \mathrm{~min}$. For presentation of timing (time schedule) of the events in the cell division cycle, we employed the morphological parameter of relative bud-length (also see DISCUSSION), a ratio of bud length to mother 


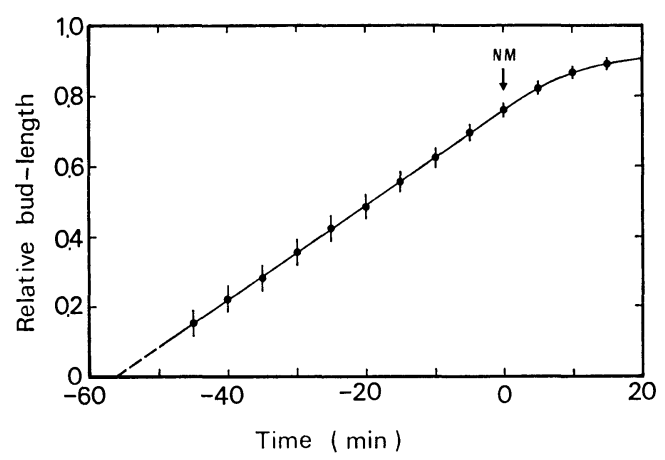

Fig. 1. Bud growth in microculture.

Pictures of cell growth in microculture (see the text) were taken at 5-min intervals, and bud growth was presented as the relative bud-length (bud-part length/mother-part length). The vertical lines in the figure denote standard error. During one generation time, mother-part having a 7.5- $\mu \mathrm{m}$ length grew to a 7.8- $\mu \mathrm{m}$ length, however, there was no growth with $8.0-\mu \mathrm{m}$ length cells. Bud-growth rate in microculture was completely equivalent to that in a liquid YS medium. NM in the figure indicates occurrence of nuclear migration

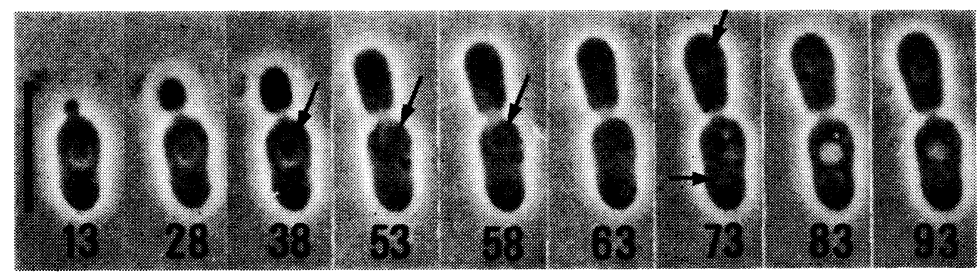

Fig. 2. Bud growth and nuclear behavior in microculture.

Nuclear behavior in a living cell is followed under a phase-contrast microscope (Leitz, Co.). Numerals in the micrographs are incubation times (min) after bud emergence. Bar, $10 \mu \mathrm{m}$. Arrow indicates nucleus.

part length. Accordingly, $\mathrm{M}$ phase occupies a time range of 0.81 to 0.87 in relative bud-length which is measurable in Giemsa-stained specimens.

The length and time schedule of $\mathrm{M}$ phase were also estimated from the timelapse observations of cell morphology and nuclear features with individual living(growing-) cells in microculture. An increase in the relative bud-length takes place at a constant rate of $0.014 / \mathrm{min}$ for $60 \mathrm{~min}$ after the occurrence of bud emergence (Fig. 1). The cells indicating a bud length of less than 0.69 are found to contain one nucleus in the central zone of the mother part, thus these cells are in Stage II. When the bud length reaches 0.76 (designated as 0 min in Fig. 1), a nucleus locates by the cell neck zone, however, at 0.82 of the bud length (which corresponds to $5 \mathrm{~min}$ in Fig. 1) the nucleus becomes invisible. In the cells having bud length of 0.87 (10 min in Fig. 1) the nuclei are still invisible in $53 \%$ of the cells examined, and in the remainder of the cells $(47 \%)$ to nuclei are visible; one is in the mother part and another in the bud part (daughter cell). According to the 
description of MCCULLY and Robinow (11), the nuclei in cells of a strain of Rhodosporidium sp. are visible under a phase-contrast microscope in a non-stained specimen (living cell) as an optically transparent region during the phases $\mathrm{G} 1, \mathrm{~S}$, and G2, while in $M$ phase the nuclei are invisible in living cells (visible in the Giemsa-stained specimens as compact form). Thus, it is stated that $\mathrm{M}$ phase of the yeast $R$. toruloides is a period of 0.81 to 0.87 in bud length (Figs. 1,2); this period corresponds to a $7-\mathrm{min}$ period of 61 to $68-\mathrm{min}$ incubations after bud emergence, as seen in Table 2. The length and timing of $M$ phase estimated by using the living-cell specimens agree almost completely with those from the Giemsa-stained ones.

Estimation of the length and timing of $S$ phase, DNA-synthesis phase

For estimation of length and timing of $S$ phase, the relationship between DNA synthesis (silver grain number) and cell morphology (relative bud-length) was examined with approximately 100 cells randomly selected from the culture in a liquid YS medium, and summarized in Fig. 3. In the figure, the maximum number of silver grains per cell, 11.3, was obtained at a relative bud-length of 0.6. However, critical estimation of both initiation and termination of DNA synthesis in asynchronous culture is impossible. In this paper, therefore, $S$ phase was defined as the period from a time showing an early half-maximum of the grain number per cell to a time showing a late half-maximum; the early and late maxima are 6.90 and 8.15 as indicated with arrows in Fig. 3, respectively. The timings of the early and late half-maxima in the cell division cycle are 0.33 and 0.69 in

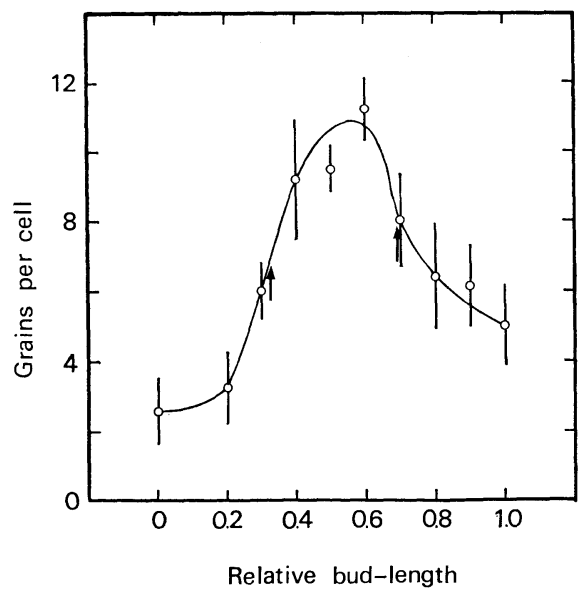

Fig. 3. Relationship between DNA synthesis and relative bud-length.

DNA synthesis is presented as silver grain number per cell. Cells in random culture were labeled with $2\left[{ }^{3} \mathrm{H}\right]$ adenine for $15 \mathrm{~min}$ followed by extraction of RNA as described in the text. The cells treated as above were employed for autoradiography. The vertical line denotes standard error. Arrows indicate $50 \%$ initiation and termination of DNA synthesis. 


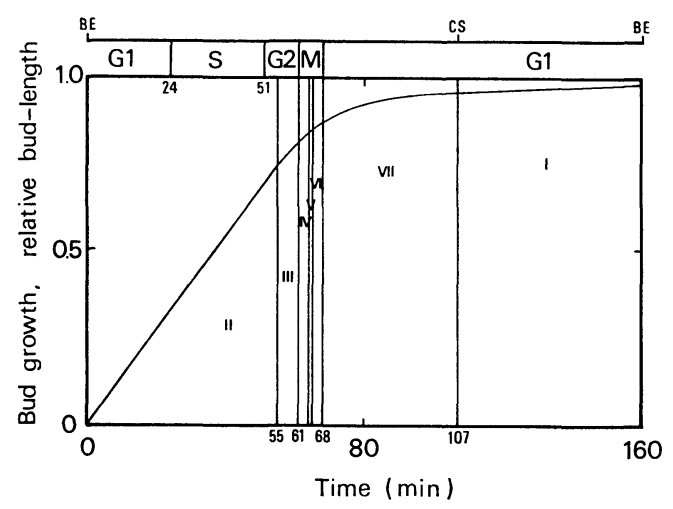

Fig. 4. Cell clock, a presentation of cell division cycle.

$\mathrm{BE}$, bud emergence; CS, cell separation; I to VII, cell stages defined in the text (see also Table 1).

relative bud-length, respectively. Thus, $\mathrm{S}$ phase is a $27-\mathrm{min}$ period of $24-$ to 51 min incubation after the occurrence of bud emergence.

Calculation of the length of $G 1$ and $G 2$ phases

According to the definition, the lengths of G1, a gap period between termination of $\mathrm{M}$ phase and initiation of $\mathrm{S}$ phase, and $\mathrm{G} 2$, a gap period of termination of $\mathrm{S}$ phase and initiation of $\mathrm{M}$ phase, are calculated to be $116 \mathrm{~min}$ and $10 \mathrm{~min}$, respectively, the timing of the phases is presented in Fig. 4.

\section{DISCUSSION}

From nuclear features (nuclear events), cell division cycle is divided into four phases, G1, S, G2 and M; phases take place in this order, achieve phase-specific functions, and build up a cycle. However, how to control the initiation and termination of each phase remains unknown. Our interest is the molecular mechanism which regulates the cell division cycle, and this paper is a preliminary report aimed at proving this subject. As described in RESULTS, we estimated the lengths of these four phases with the exponentially growing cells of the haploid yeast Rhodosporidium toruloides in a YS medium, a rich medium, at $27^{\circ} ; \mathrm{G} 1, \mathrm{~S}$, G2 and $\mathrm{M}$ phases are 116, 27, 10, and $7 \mathrm{~min}$, respectively. BARFORD and HALL (9) described in their report that the respective phases of the yeast Saccharomyces cerevisiae $\mathrm{Y}-31$ are $9.0,45.5,22.3$, and $15.7 \mathrm{~min}$ in a glucose-synthetic medium giving a generation time of $92 \mathrm{~min}$, and the lengths of $\mathrm{S}, \mathrm{G} 2$, and $\mathrm{M}$ phases are not affected by growth medium, while the length of G1 depends on the medium. Thus, it might be stated that $\mathrm{S}, \mathrm{G} 2$, and $\mathrm{M}$ phases of $R$. toruloides are significantly short and $\mathrm{G} 1$ phase is extremely long. In the division yeast, Schizosaccharomyces pombe Lindner, G2 phase occupies a long term in the cell division cycle (12). 
From cellular features (cellular events), the cell division cycle is found to consist of four cell-morphological events, bud emergence, bud growth, bud maturation (cease in bud growth), and cell separation. Therefore, we would like to summarize the nuclear and cellular events in a cell-clock (Fig. 4) in which 0 hour is defined as the time of initiation of bud emergence. The 0 hour can be readily calculated from the ratio of increase in relative bud-length (Fig. 1).

As seen in the cell clock (Fig. 4), the relative bud-length reaches a plateau during an early G1 phase, followed by maturation of the bud to be the daughter cell. Cell separation takes place at a middle G1 phase. During the 53 min after cell separation, little alteration in cell morphology is observed. Then bud emergence and bud growth occur, and initiation of chromosomal DNA synthesis is induced. These phenomena suggest that some extent of activation in macromolecular syntheses, such as protein and ribosomal RNA syntheses, should be required late in the G1 phase. Recently, we isolated the temperature-sensitive cell division cycle mutants ( $c d c$ mutants) of $R$. toruloides and pointed out that G1-specific maintenance of ribosomal-RNA polymerase at an activating level is essential for progression of the cell division cycle by using a G1-defective $c d c$ mutant strain B2-39 (6).

In higher eukaryotic cells, $\mathrm{M}$ phase is defined as the period from initiation of chromatin condensation to completion of nuclear division, and these chromosomal events are visible under a light microscope without staining. However, in the yeasts Saccharomyces sp. (13) and Rhodosporidium sp. (11), the condensed chromatin-fibers are invisible under the microscope. An exact separation, therefore, of M phase from G1 and G2 phases with clear boundaries is somewhat difficult from direct observation of living yeast cells. In the budding yeasts, a characteristic migration of the nucleus from the central zone of the mother part to a neck zone of the bud part takes place for intracellular arrangement of the nucleus prior to the occurrence of nuclear condensation-and-division. For this reason, nuclear migration has been used as a parameter for definition of cell stage. However, confusion on the definition of cell stage relating to cell phase occurred in the following example: Stage III, in which nuclear migration takes place as an expanded form, is included in M phase by BARFORD and HaLL (9), and in G2 phase by Hartwell (14). In Saccharomyces cerevisiae, it was found that migration and duplication (condensation and division) of the nucleus are controlled by independent mechanisms (15). Moreover, the independence was also proved in the yeast used here (5) from the following observation: two nuclear events, migration and duplication, occur in this order with a significantly high frequency of the reversed order, approximately $10 \%$. In this paper, therefore, $\mathrm{M}$ phase was defined as a cellular period indicating the compact form of nucleus in Giemsastained specimens.

The length of $\mathrm{S}$ phase was calculated autoradiographically from silver grain number in Fig. 3, in which 15-min radio-labeling of DNA with adenine was 
performed. Little labeling of DNA takes place for the first 10-min incubation with adenine, then high labeling follows. Subsequently, the activity of DNA synthesis determined here is the activity during the last $5 \mathrm{~min}$ of incubation. In the figure, the estimation of cell stages was carried out from cell morphology at the termination time of the labeling, therefore, we did not do any correction for presentation of the time schedule of $\mathrm{S}$ phase.

\section{REFERENCES}

1) K. Abe, I. Kusaka and S. Fukui, J. Bacteriol., 122, 710 (1975).

2) Y. Kamiya, A. Sakurai, S. Tamura, N. Takahashi, K. Abe, E. Tsuchiya and S. Fukui, Agric. Biol. Chem., 42, 1239 (1978).

3) Y. Kamiya, A. Sakurai, S. Tamura, N. Takahashi, K. Abe, E. Tsuchiya, S. Fukui, C. Kitada and M. Fujino, Biochem. Biophys. Res. Commun., 83, 1077 (1978).

4) C. Kitada, M. Fujino, Y. Kamiya, A. Sakurai, S. Tamura, N. Takahashi, E. Tsuchiya, K. ABE and S. Fukui, Experientia, 35, 1275 (1979).

5) K. Abe, E. Tsuchiya, I. Kusaka, S. Fukui and A. Kusanagi, J. Gen. Appl. Microbiol., 23, 175 (1977).

6) I. Yamashita and S. Fukui, J. Bacteriol., 144, 772 (1980).

7) I. Banno, J. Gen. Appl. Microbiol., 13, 167 (1967).

8) E. O. Powell, J. Gen. Microbiol., 15, 492 (1956).

9) J. P. BARFord and R. J. HAll, Exp. Cell Res., 102, 276 (1976).

10) D. H. Williamson, J. Cell Biol., 25, 517 (1965).

11) E. K. McCully and C. F. Robinow, J. Cell Sci., 11, 1 (1972).

12) P. Nurse, P. Thuriaux and K. Nasmyth, Mol. Gen. Genet., 146, 222 (1976).

13) C. F. Robinow and J. Marak, J. Cell Biol., 29, 129 (1966).

14) L. H. Hartwell, Bacteriol. Rev., 38, 164 (1974).

15) L. H. Hartwell, J. Culotti, J. R. Pringle and J. Reid, Science, 183, 46 (1974). 